\title{
Factors Affecting Knowledge Sharing in the University of The Gambia
}

\author{
Saikou Sanneh ${ }^{1}$, and Chih-Chien Lai ${ }^{2}$ \\ Graduate Institute of International Human Resource Development \\ National Taiwan Normal University
}

\begin{abstract}
Knowledge sharing (KS) among employees is gaining momentum in organizations of various types and sizes. However, previous researches highlighted that there is limited research on KS in universities. Therefore, the focus of this study is to explore the factors that affect knowledge sharing in The University of The Gambia (UTG) thereby contributing to the limited literature. The researcher used the qualitative approach to collect the data. To triangulate, fifteen (15) UTG staff including lecturers and administrators from various schools and levels were interviewed one on one. Their durations of working at UTG range between 1 year and 11 years. The findings of the research indicated that the factors that affect KS in UTG include: lack of KS platforms, Lack of funding for research, lack of administrative support, willingness and or unwillingness of people, trust and confidentiality, Arrogance, and Internet Availability. These factors were categorised into three (3) main dimensions such as organizational factors, personal factors and technological factors. This study suggests that the UTG authorities should create that conducive environment in terms of the provision of knowledge sharing platforms as well as provision of funds and internet connection for all its staff in order to tap into their various tacit knowledge and expertise for better service delivery.
\end{abstract}

Keywords: organizational culture, trust, information and communication technology, KS, university

\section{Introduction}

A university is a centre of learning and development. It is a place where knowledge is created and also shared. The phenomenon of knowledge sharing is growing in popularity and posterity. This is as a result of its relevance to enhancing organizational growth. KS gives organizations that competitive advantage [1].

Knowledge can be classified into two groups-tacit and explicit [1]. The tacit knowledge refers to that unique knowledge possessed and stored in an individual's head. It is that valuable component of knowledge that is mostly needed but cannot be easily accessed or transferred. It is the one that should be considered more valuable [2]. On the other hand, explicit knowledge refers to that kind of knowledge that is not restricted and is usually codified. A clear example given for this is an instructional manual or knowledge repository. The concept of knowledge sharing has gained a momentum in organizations of all types and sizes. Meanwhile, despite the fact that organizations are toiling to set up knowledge management systems and practices so as to effectively utilize the available knowledge, there is still much to be learned and known as to how knowledge is created, share, and used in these organizations [3].

There is very limited research conducted on knowledge sharing in universities even though the universities are believed to be the centres of knowledge creation and dissemination [4]. This paper therefore, aims to explore the factors that affect knowledge sharing in the University of The Gambia (UTG). Knowledge sharing can be defined as exchanging experiences, events, thoughts or understanding of anything (in general) with an expectation to gain more insights and understanding about something for temporary curiosity [5]. Through knowledge sharing, the individual's tacit knowledge which is unique to him and sometimes very difficult to be accessed, turns into tacit knowledge for another person or party [6].

According to the research by [4] on knowledge sharing amongst academics in UK universities, there is a strong body of research conducted on knowledge management and knowledge sharing in commercial environments as well as in the public sector organizations. However, the trend of research into knowledge management and knowledge sharing is very limited in universities. As a result, in the year 2000 according to 
Rowley as quoted by the research [4], the question that was posed was 'Is higher education ready for knowledge management?'

\section{Literature Review}

The review of the literature revealed that the concept of knowledge sharing in organization is affected by several factors which could be categorized into organizational culture, trust and Information and communication technology. Therefore, the review of the literature for this research paper focused on these three aspects, and their relation to knowledge sharing.

\subsection{Organizational Culture}

The concept of culture is being used by people in all spheres of life as it suits that particular group. As such, there are manifold definitions of organizational culture. However, almost all of the most widely accepted ones are similar and cover many of the same aspects. Organizational Culture generally refers to the culture that exists in the Organization.

Organizational culture was defined as "A pattern of shared basic assumptions that the group learned as it solved its problems that has worked well enough to be considered valid and is passed on to new members as the correct way to perceive, think, and feel in relation to those problems." [7] Organizational culture comprises different categories or components. And organizational culture involves six major categories: information systems, people, process, leadership, reward system and organization structure [8].

Organizational culture is seen as one of the factors that strongly affect effective knowledge creation, sharing and use among employees in an organization. In addition, the culture of the organization determines the norms regarding knowledge sharing among and between employees in that organization [9]. Organizational culture is the culture that tells one what to do and what not to do regarding the processing of knowledge and the manner in which it should be communicated in organization [10]. Similarly, an organization's culture does also shape the perceptions and behaviours of its employees, and it does this by establishing the context for social interactions within that particular organization [7]. The norms and practices in an organization that promote individual ownership of knowledge, will severely hinder the process of knowledge sharing within that particular organization because organizational culture orients the mindset and action of every individual employee [10]. According to the explanation, organizational values that influence knowledge sharing include the creation of a sense of involvement and contribution among employees [11].

\subsection{Trust}

Trust is "a set of beliefs about the other party (trustee), which leads one (trustor) to believe that the trustee's actions will have positive consequences for the trustor's self" [12]. They opined that if employees trust each other, then they are ever ready and willing to make their knowledge available to each other. Previous researchers [13] acknowledged the fact that an individual's desire and willingness to share his or her knowledge with the colleagues in an organization is indeed positively influence by trust.

Trust among employees, and co-workers in particular is very instrumental in ensuring successful knowledge management and sharing. It is believed that the readiness of an organization's employees to share their tacit knowledge is highly dependent on their trust of the recipient of that knowledge. For an organisation to ensure the free flow of knowledge between its employees and also from employees into the institution's general database, there should exist that bond of trust between the employees as between the organization's different functions [12]. This indicate that trust is an essential ingredient in promoting knowledge sharing among employees in an organization.

\subsection{Information and Communication Technology (ICT)}

In contemporary business environment, and organizations or institutions of any type, the use of ICT in executing and implementing policies and programmes is indeed indispensable, particularly an organization that 
wants to promote and encourage knowledge sharing among its employees. Information Communication Technology is defined as a software and hardware that people in organizations use in order to do their tasks [14]. They continued to explain that the most relevant aspect of ICT in knowledge sharing is to serve as a bridge between and among people that acquired knowledge. The significant role of ICT in KS is 'to connect people with other people or with explicit knowledge' [15]. There are three different issues identified that are related to knowledge sharing in relation to Information and Communication Technology [16]. They stated ICT tools, ICT infrastructure and ICT know-how.

In order to ensure that there is effective and efficient knowledge management practice and a resilient knowledge management system, employees should be determined, ready and willing to share their knowledge through the use of computer gadgets that can be made accessible to all and sundry within the organization.

\subsection{Knowledge Sharing}

Organizational knowledge sharing entails dissemination of knowledge between and among employees. Also, KS can be defined as exchanging experiences, events, thoughts or understanding of anything (in general) with an expectation to gain more insights and understanding about something for temporary curiosity [5]. KS contributes to individual and organizational learning [13].

On the contrary, the absence of knowledge sharing serves as an obstacle to the effective management of knowledge in organizations [17]. This indicates that lack of knowledge sharing can breed inefficiency and ineffectiveness in an organization. There also exists positive relationship between rewards and knowledge sharing in organizations [18]. They however, highlighted trust, communication between staff, information systems, reward system and organizational structure as some factors that influence the successful knowledge sharing.

There is limited research on knowledge management and knowledge sharing in public organizations and universities for that matter [19]. There is no study on the level and nature of knowledge sharing in the University of The Gambia, and knowledge sharing among employees in an organization has lot of benefits which helps towards achieving organizational goals. For the purpose of this paper, knowledge sharing is referred to as process that involves the exchange of knowledge between and among UTG staff for effective service delivery.

\section{Research Methods}

The main purpose of this study is to explore the factors that affect knowledge sharing in The University of The Gambia (UTG). The researcher used the qualitative approach to collect the needed data. The researcher used questions that he adopted from previous researches related to knowledge sharing in public organisations and edited them which were then reviewed by two experts. Nine interview questions were used.

\subsection{Data Collection and Analysis}

Fifteen (15) UTG staff were interviewed. These staff with various university ranks were selected from the university's various schools including some administrative staff. The data collection was done using convenient sampling as the interviewees were interviewed based on their convenient schedules. Five (5) of the respondents were women while the rest (10) were men. The number of years that each interviewee spent with UTG ranges between 1 year and 11 years. The interviews were done on different dates and times based on the convenient schedules of the interviewees.

The interviewer recorded the interviews in his notebook while at the same time used an electronic device to do the recordings as well. The analytical procedure was done using the thematic approach. This was done based on the themes that emerged from the various respondents.

\subsection{Validity}

The validity of a research entails the whole research concept and tells you if the findings truly meet the standards. That depicts how the collected data replicates the phenomenon being examined which eventually 
enhances the credibility of the study [20]. In order not to compromise with the validity of this research, the questions were adopted from previous related research. In addition, to further ensure its validity, the data was collected from lecturers in the various schools of UTG whose work experiences and ages differ. This was done in order to minimize or avoid subjectivity in its entirety.

\subsection{Reliability}

Reliability entails the research results being significant and be more than a one-off finding and be inherently repeatable. In addition, other researchers should use the exact experiment with the same conditions attached and eventually results into the same or similar findings. Reliability is very important in a study because it determines the overall validity of the research which enhances and strengthens the findings [21]. Therefore, a thematic approach of analysing the qualitative data was used. The data collected from the UTG staff was done through note taking and recording using an electronic device. In order to ensure high standard, the recorded interviews were all transcribed. After the transcription, it was then categorised and analysed so as to get rid of biasness. This process also adds up to the reliability of the findings.

\section{Findings and Discussions}

The results revealed a range of factors that affect KS at UTG. They include: lack of KS platforms, Lack of funding for research, lack of administrative support, willingness and or unwillingness of people, trust and confidentiality, Arrogance, and Internet Availability. These debilitating factors are basically categorised into three main dimensions of Organizational factors, personal factors and Technological Factors [15].

\subsection{Organizational Factors}

\subsubsection{Lack of a platforms for KS}

In lot of universities, they create platforms such as journals in the form of print and online. However, according to the respondents, particularly the lecturers, lack of a specific platform in UTG such as an academic journal where they can publish their research works to make them accessible among themselves is one of the factors that affects knowledge sharing. A respondent complained that 'In some universities, they create some platforms. A special platform is created to be able to share knowledge. The absence of journal in our universityboth online and print so as to be able to help us share knowledge among ourselves is a major limitation'. Similar sentiment was expressed by another person 'there is no academic journal within UTG where research papers can be published.

\subsubsection{Lack of funding for research}

Academics have a great role to play in knowledge creation and sharing through research and publication. A good number of the respondents agreed that there's little or no budget allocated by the university authorities for the staff to be conducting research and publication. The respondents believed that the authorities are not fully taking their stance as there are no funds at the disposal of the staff who are willing to conduct researches and share their findings. As one of the respondents put it 'there's lack of funds to conduct research and publication.' Another respondent echoed similar sentiment and said 'there is resource constraints and lack of available infrastructure.'

\subsubsection{Lack of administrative support.}

According to [18] there is positive relationship between rewards and knowledge sharing in organizations. However, at UTG, there is lack of reward system in place for people who share their knowledge with colleagues for effective and efficient service delivery. The other issue is that there is 'lack of commitment from UTG administrators' one of the respondents highlighted which was supported by almost all the respondents. It is also worth mentioning that leadership support is a key component in KS. Leaders serve as role models when it comes to KS, and they are also the ones that provide incentives for it. Similarly, leaders ensure that there is conducive environment which facilitate other members to create the necessary knowledge locally [23]. 
Moreover, it is also important to note that putting in place a reward system for KS plays a very crucial role in encouraging organizational knowledge sharing practice. The idea of reward system in encouraging knowledge sharing was confirmed by [22]. They affirmed that organizational rewards serve as source of motivation for employees to share their knowledge and foster that environment of knowledge culture. They further asserted that indirect rewards such as appreciation and recognition play a greater role than the monetary incentives in KS. And one of the respondents highlighted that 'the administration can encourage KS by merely recognizing and appreciating the efforts of those who share by awarding them during graduation ceremonies'.

\subsection{Personal Factors}

\subsubsection{Willingness/ unwillingness}

'If the individual that I try to share my knowledge with is not willing to listen or to get knowledge from me, why will I bother myself or the person?' This was the view of one of the respondents. Similarly, almost all of the respondents highlighted the willingness of the recipient as a very crucial component in knowledge sharing. 'Nothing discourages me from sharing as long as the individual is ready and willing' a respondent stressed. The researchers [13] acknowledged the fact that an individual's desire and willingness to share his or her knowledge with the colleagues in an organization is indeed positively influence by trust.

\subsubsection{Confidentiality and trust}

A lot of research findings acknowledged that trust is positively related to knowledge sharing practice in organizations. An individual's personality can either facilitate or hinder knowledge sharing. However, in this research, most of the respondents said they are not much concerned about the issue of trust. This could be attributed to the fact that the type of knowledge they share is related to academic issues which makes it different from that of other organizations.

The respondents consistently used the term 'confidentiality', and 'confidentiality is a set of rules or a promise that limits access or places restrictions on certain types of information (WhatIs.com). They clarified that the receiver's willingness to ensure 'confidentiality' will go a long way in giving the sharer the readiness to disseminate his knowledge. 'If I know there will be no confidentiality then I won't share my knowledge' said respondent. According to the explanation of [12] the readiness of an organization's employees to share their tacit knowledge is highly dependent on their trust of the recipient of that knowledge.

\subsubsection{Arrogance}

The term arrogance was used by almost all the respondents. Arrogance is defined as 'an insulting way of thinking or behaving that comes from believing that you are better, smarter, or more important than other people' (Merriam-Webster). Speaking with a very strong tone, one of the longest serving staff as far as the people interviewed in this study are concerned emphatically stressed 'I don't share my knowledge with my boss or colleague if he's arrogant or if he feels he knows everything, or if he thinks I know nothing, then I'll not share anything with him'. Another respondent said 'If I realise that a person feels he knows everything or is someone who does not want to take what I know just because it contradicts his' he added 'if they are willing to learn and not someone who thinks he knows everything' then he is always ready to share. This is similar to the findings of a previous study conducted by [6] in their study of determinants of knowledge sharing in a public sector institution in Ghana. One of their respondents asserted that '...lack of humility and the show off of all knowing abilities would put me off from sharing my knowledge’ (p.39).

\subsection{Technological Factor- Availability of Internet}

In any organization, information and communication technology (ICT) plays a very crucial part in knowledge sharing. This has been manifested in the responses of these research participants. Accessibility to internet is sometimes very hard. And effective KS is highly dependent on the readiness of employees to share 
their knowledge through computer facilities that is made available and accessible to all the employees within the organization [16].

According to one of the lecturers, UTG has provided data cards to most of its employees including lecturers. These data cards are provided courtesy of one of the mobile network operators called QCell. However, there is still a substantial number of its staff that do not own a data card, and even those who own one, sometimes the internet connection is poor that sharing some educational materials or exchanging ideas through email and social media becomes futile.

According to [14] as cited by [15], infrastructure is a necessity in creating knowledge, knowledge structure, knowledge penetration as well as knowledge use. One of the respondents stated 'we're still a young and growing university, and as such, we have some facility challenges. There is sometimes unavailability of relevant textbooks, and when we resort to the internet to get access to the online materials, the 'internet is not too good' and that makes it difficult to download books'. Another respondent buttressed the idea that internet accessibility is an issue for the UTG lecturers. He acknowledged that 'positive strives have been made in UTG, for example, the provision of data cards to lecturers, but some lecturers, and graduate assistants are still without it'.

\section{Conclusions and Implications}

If the findings of this research and other previous researches are anything to go by, then there is no doubt that knowledge is meant to be shared. However, in order to ensure effective KS at UTG, the authorities need to be aware of those factors that hinder this good practice. A lot of research has been done on the area of KS in organizations but not much on universities. This study therefore, explored those factors that affect KS in The University of The Gambia, and the findings eventually brings into limelight those key factors as lack of KS platforms, Lack of funding for research, lack of administrative support, willingness and or unwillingness of people, confidentiality and trust, Arrogance, and Internet Availability. Based on the analysis, the findings of this study categorised these various factors into three main dimensions-organizational factors, personal factors and technological factors.

The respondents expressed their readiness to always share their knowledge but the highlighted findings of this study serve as an obstacle to that course. In order to ensure that the knowledge possessed by various individuals at UTG are maximally shared and used, the researcher suggests that the authorities should be willing to provide funds that will be utilised for research. In the same vein, the issue of internet accessibility should be addressed. Those staff without data cards should also be provided with and the authorities liaise with the internet provider to work on improving the speed of the available internet. Similarly, the authorities should also try and create a platform for paper publication which can serve as one of the venues for knowledge sharing. This will encourage the staff to conduct regular research work because they will know that they have a ready platform where it can be published without much obstacles.

Finally, this research revealed the factors that affect KS in UTG. However, on the issue of future research on knowledge sharing concerning UTG, further research can be conducted using quantitative approach where a good number of all the staff can be captured. Future studies could also focus on comparing the level of knowledge sharing between the various schools of UTG.

\section{Acknowledgements}

I would like to express my sincere gratitude and appreciation to the Director of IHRD program (Dr. Rosa Yeh) and her entire staff. Similarly, I would also like to thank a friend and a staff at UTG- Mr. Yankuba E. Manneh for facilitating the conduct of the interviews and for the valuable suggestions offered during the course of the data collection. 


\section{References}

[1] I. Nonaka and H. Takeuchi, The Knowledge-creating Company: How Japanese companies create the Dynamics of Innovation, Oxford University press, 1995, ch.1, pp. 6-10.

[2] I. Reychav and J. Weisberg, "Bridging intention and behavior of knowledge sharing," Journal of Knowledge Management, vol. 14(2), pp. 285-300, July 2010.

https://doi.org/10.1108/13673271011032418

[3] H. Tsoukas and E. Vladimirou, "What is organizational knowledge?" Journal of Management Studies, vol. 38 (7), pp. 973-993, 2001. https://doi.org/10.1111/1467-6486.00268

[4] R. Fullwood, J. Rowley, and R. Delbridge, "Knowledge sharing amongst academics in UK universities," Journal of Knowledge Management, vol. 17(1), pp.123-136, October 2013.

https://doi.org/10.1108/13673271311300831

[5] M. S. Sohail, and S. Daud, "Knowledge sharing in higher education institutions: Perspectives from Malaysia," Vine, vol. 39 (2), pp.125-142, 2009.

https://doi.org/10.1108/03055720910988841

[6] H. Boateng and F. G. Agyemang, "A qualitative insight into key determinants of knowledge sharing in a public sector institution in Ghana," Information Development, vol. 32 (1), pp. 35-43, January 2016.

https://doi.org/10.1177/0266666914525650

[7] E. H. Schein, Organizational Culture and Leadership, Vol. 356. John Wiley \& Sons, 2006, Ch.1, pp. 3-17.

[8] A. K. Gupta and V. Govindarajan, "Knowledge flows within multinational corporations," Strategic Management Journal, vol. 21(4), pp.473-496, April 2000.

https://doi.org/10.1002/(SICI)1097-0266(200004)21:4<473::AID-SMJ84>3.0.CO;2-I

[9] R. McDermott and C. O'dell, "Overcoming cultural barriers to sharing knowledge," Journal of Knowledge Management, vol. 5(1), pp.76-85, 2001.

https://doi.org/10.1108/13673270110384428

[10] M. Ipe, "Knowledge sharing in organizations: A conceptual framework," Human Resource Development Review, Vol. 2(4), pp. 337-359, December 2003.

https://doi.org/10.1177/1534484303257985

[11]C. O'dell and C. J. Grayson, "If only we knew what we know: Identification and transfer of internal best practices," California Management Review, vol. 40(3), pp. 154-174, 1998.

https://doi.org/10.2307/41165948

[12]Z. M. Islam, I. Hasan, S. U. Ahmed, and S. M. Ahmed, "Organizational culture and knowledge sharing: Empirical evidence from service organizations," African Journal of Business Management, vol. 5 (14), pp. 5900-5909. July 2011.

[13] K. M. Andrews and B. L. Delahaye, "Influences on knowledge processes in organizational learning: The psychosocial filter, ” Journal of Management Studies, vol.37 (6), pp.797-810, September 2000.

https://doi.org/10.1111/1467-6486.00204

[14] Van den Hooff, B., Elving, W., Meeuwsen, J. M., \& Dumoulin, C., "Knowledge sharing in knowledge communities, In Communities and technologies," Springer Netherlands, pp. 119-141, 2003.

https://doi.org/10.1007/978-94-017-0115-0_7

[15] M. B. Ismail and Z. M. Yusof, "Knowledge sharing models: Do they really fit public organizations?” International Symposium on Information Technology, IEEE, vol. 2, pp. 1-9, August 2008.

https://doi.org/10.1109/itsim.2008.4631661

[16] S. O. Syed-Ikhsan and F. Rowland, "Knowledge management in a public organization: a study on the relationship between organizational elements and the performance of knowledge transfer," Journal of Knowledge Management, vol. 8 (2), pp. 95-111, 2004.

https://doi.org/10.1108/13673270410529145

[17] T. H. Davenport and L. Prusak, "Working knowledge: How organizations manage what they know," Harvard Business Press, 1998, ch.1 pp. 23-24.

[18] A. I. Al-Alawi, N. Yousif Al-Marzooqi, and Y. Fraidoon Mohammed, "Organizational culture and knowledge sharing: critical success factors,” Journal of knowledge management, vol. 11(2), pp. 22-42, 2007. 
https://doi.org/10.1108/13673270710738898

[19] R. McAdam and R. Reid, "A comparison of public and private sector perceptions and use of knowledge management," Journal of European Industrial Training, vol. 4(6), pp.317-329, August 2000. https://doi.org/10.1108/03090590010346424

[20] J. Collins and R. Hussey, Business Research: A Practical Guide for Undergraduate and Post Graduate Students, $2^{\text {nd }}$ ed. New York: Palgrave Macmillan, 2003 ch.3, pp. 53-55.

[21] R. K. Yin, Case Study Research, Design and Methods, 5th ed. Thousand Oaks, CA: SAGE, 2008, ch.1, pp. 27-30.

[22] S. Oliver and Reddy Kandadi, K., "How to develop knowledge culture in organizations? A multiple case study of large distributed organizations," Journal of knowledge management, vol. 10(4), pp. 6-24, 2006. https://doi.org/10.1108/13673270610679336

[23] Kreiner, K., “Tacit knowledge management: the role of artifacts, ” Journal of Knowledge Management, vol. 6(2), pp.112-123, 2002.

https://doi.org/10.1108/13673270210424648 